\title{
Phosphene-guided transcranial magnetic stimulation of occipital but not parietal cortex suppresses stimulus visibility
}

\author{
Evelina Tapia $^{1,{ }^{*}, \text { Chiara Mazzi }^{2}, \text { Silvia Savazzi }^{2} \text {, and Diane M. Beck }}{ }^{1}$ \\ ${ }^{1}$ Department of Psychology, Beckman Institute, University of Illinois, Urbana, IL, USA \\ ${ }^{2}$ Department of Neurological and Movement Sciences, Section of Physiology and Psychology, \\ University of Verona, Verona, Italy
}

\begin{abstract}
Transcranial magnetic stimulation (TMS) applied over the occipital lobe approximately $100 \mathrm{~ms}$ after the onset of a stimulus decreases its visibility if it appears in the location of the phosphene. Because phosphenes can also be elicited by stimulation of the parietal regions, we asked if the same procedure that is used to reduce visibility of stimuli with occipital TMS will lead to decreased stimulus visibility when TMS is applied to parietal regions. TMS was randomly applied at 0 to $130 \mathrm{~ms}$ after the onset of the stimulus (SOA) in steps of $10 \mathrm{~ms}$ in occipital and parietal regions. Participants responded to the orientation of the line stimulus and rated its visibility. We replicate previous reports of phosphenes from both occipital and parietal TMS. As previously reported, we also observed visual suppression around the classical $100 \mathrm{~ms}$ window both in the objective line orientation and subjective visibility responses with occipital TMS. Parietal stimulation, on the other hand, did not consistently reduce stimulus visibility in any time window.
\end{abstract}

\section{Keywords}

TMS; TMS masking; phosphenes; scotomas; occipital cortex; parietal cortex; visual masking

\section{INTRODUCTION}

For over 20 years transcranial magnetic stimulation (TMS) has been used to study cortical dynamics in the occipital lobes of human participants. Stimulation of the occipital cortex often results in sensations of phosphenes that are small, brief and faint flashes of light that occur in the absence of an external source of light (e.g. Barker, Freesto, Jalinous, Merton, \& Morton, 1985; Kammer, 1999; Marg \& Rudiak, 1994). In addition to phosphenes, TMS over the occipital cortex can also produce artificial and transient scotomas. These perceptual phenomena are described as transient visual field defects (Kammer, 1999; Kammer, Puls, Erb, \& Grodd, 2005a; Kastner, Demmer, \& Ziemman, 1998), darker spot in the visual field (Fernandez et al., 2002; Morgan, 1999), or a region missing in a visual pattern (Kamitani \& Shimojo, 1999; Murd, Luiga, Kreegipuu, \& Bachmann, 2010).

\footnotetext{
“Correspondence: Beckman Institute, University of Illinois, 405 N. Mathews Ave., Urbana, IL 61801, USA, evelina@illinois.edu.
} 
Phosphenes and scotomas typically appear in the same retinotopic location (Kammer, 1999; Kastner, Demmer, \& Ziemann, 1998) and are thought to result from stimulation of the same brain structures in the early visual cortex, primarily V1-V3 (Cowey \& Walsh, 2000;

Kammer et al., 2005a; Thielscher, Reichenbach, Uğurbil, \& Uludağ, 2010). Similarly, it has been argued that both phosphenes and scotomas might result from TMS reaching the optic radiations that terminate in the early visual cortex as well as areas that are interconnected with V1-V3 (Kammer, 2007; Kastner, Demmer, \& Ziemann, 1998; Marg \& Rudiak, 1994). Although the functional mechanisms that give rise to these percepts is thought to differ especially because of the distinct perceptual qualities (i.e. flash of light vs. flash of darkness) of these phenomenon, it is clear they share a close relationship. Some have argued that phosphenes arise due to TMS excitation of the occipital neurons (Kammer et al., 2005a; Marg \& Rudiak, 1994), whereas scotomas arise due to inhibition of the neurons (Amassian, Cracco, Maccabee, Cracco, Rudell, \& Eberle, 1989; Kammer, Puls, Strasburger, Hill, \& Wichmann, 2005). Most recent evidence, however, suggests that phosphenes and scotomas both occur due to neuronal excitation and that subjective experience of such TMS-induced percepts (i.e. phosphene or scotoma) depends on external factors such as background luminance (Knight, Mazzi \& Savazzi, 2013).

Regardless of the exact mechanisms, it is clear that TMS of the same occipital location can produce both kinds of percepts and so one is often used to localize the other. Specifically, one of the standard procedures in scotoma or visual suppression studies is to first find a location near the occipital pole that elicits an experience of a phosphene. Then, visual stimuli are presented at the same location in space as the phosphene and participants are asked, for example, to discriminate the stimuli or rate their visibility (e.g. Jacobs, Goebel, \& Sack, 2012; Kammer et al., 2005b; Sack, van der Mark, Schuhmann, Schwarzbach, \& Goebel, 2009). Such procedures have proved successful in visual suppression studies; stimuli are rendered less visible in several distinct time windows when TMS is applied to the occipital cortex (e.g. Amassian et al., 1989; Corthout, Uttl, Walsh, Hallett, \& Cowey, 1999; Corthout, Uttl, Ziemann, Cowey \& Hallett, 1999; de Graaf, Herring, \& Sack, 2011; Jacobs, Goebel, \& Sack, 2011; Kammer, 2007). TMS reduction of stimulus visibility at around 100 $\mathrm{ms}$ after stimulus onset is often referred to as the classical TMS suppression window. It is generally accepted that this visual TMS masking effect arises from the same mechanism that elicits scotomas (Amassian et al., 1989; Kammer et al., 2005b).

Recently it was shown that phosphene sensations can also be elicited with TMS applied over the parietal in addition to occipital cortex, i.e. regions corresponding to the P3/P4 electrode sites (Marzi, Mancini, \& Savazzi, 2009) which map onto Brodmann's areas 7 and 40 (Herwig, Satrapi, \& Schönfeldt-Lecuona, 2003). These sensations are described as similar to occipital phosphenes (Fried, Elkin-Frankston, Rushmore, Hilgetag, \& Valero-Cabre, 2011), although occipital phosphenes are sometimes brighter or more vivid (Mazzi, Mancini, \& Savazzi, under review). The mechanism that gives rise to parietal phosphenes is currently not known. TMS to parietal cortex areas that are known to elicit phosphenes results in activity in occipital cortex 20-40 ms after stimulation (Parks et al., 2013). The presence of parietal phosphenes as well as occipital activity after stimulation of the parietal areas that generate phosphenes are both in line with known neural connections between parietal and 
occipitotemporal regions (Felleman \& Van Essen, 1991; Lewis \& Van Essen, 2000; Webster, Bachevalier, \& Ungerleider, 1994), and the fact that certain parietal regions are selective for visual stimuli (Konen \& Kastner, 2008; Orban et al., 2006; Silver \& Kastner, 2009; Silver, Ress, \& Heeger, 2005; Swisher, Halko, Merabet, McMains, \& Somers, 2007). These data are consistent with the idea that occipital and parietal phosphenes might arise from the same neural mechanisms (Fried et al., 2011). However, parietally-induced phosphenes have also been reported in the blind visual field of two hemianopic patients (Mazzi, Mancini, \& Savazzi, under review), raising the possibility that parietal phosphenes arise from a distinct mechanism that leads to occipital phosphenes.

Given that occipital phosphenes and scotomas are closely linked and might arise from an identical neural mechanism (Knight, Mazzi, \& Savazzi, 2013, and under review), here we investigate whether TMS to the parietal areas that elicit sensations of phosphenes also produces scotomas. We assess the presence of parietal scotomas by employing a standard TMS masking procedure used to reduce visibility of stimuli with occipital TMS. To anticipate the results, we find that TMS over occipital areas, at levels that elicit phosphenes, also reduces visibility of small line stimuli in the usual stimulus-to-TMS time windows, whereas TMS of the parietal areas, also under conditions that elicit phosphenes, fail to reduce visibility of stimuli in a consistent and comparable manner.

\section{METHOD}

\section{Participants}

110 participants, University of Illinois Urbana-Champaign students and Urbana-Champaign area residents, were screened for occipital and parietal phosphenes. All had normal or corrected-to-normal vision and were under 35 years of age. TMS was applied within $2 \mathrm{cms}$ of electrode locations $\mathrm{O} 1 / \mathrm{O} 2$ for occipital and $\mathrm{P} 3 / \mathrm{P} 4$ for parietal regions. Of the 110 participants, 23 did not experience occipital phosphenes. Of the 85 who experienced occipital phosphenes, 50 also reported parietal phosphenes. Of these 50, 27 had parietal phosphenes that were too peripheral, faint, inconsistent in location across different stimulation trials, and/or required stimulation intensities above the capacity of the stimulator (see Design and TMS parameters) to be included in the stimulus discrimination and visibility rating phase of the experiment. The remaining 23 participants reported stable phosphenes within $6^{\circ}$ of visual angle from fixation elicited by stimulation of both the occipital and parietal lobe of the same hemisphere. Of these, 18 (15 right-handed) completed all sessions of the experiment. Participants were paid $\$ 16$ per hour of their time.

\section{Stimuli and Procedure}

The stimuli were generated using E-Prime 2.0 software (Psychology Software Tools, Pittsburgh, PA) and presented against at light grey $\left(22 \mathrm{~cd} / \mathrm{m}^{2}\right)$ background on a $19^{\prime \prime}$ Sony CRT monitor with a refresh rate of $100 \mathrm{~Hz}$. The synchronization between TMS and the stimulus computer was verified prior to the start of the experiment using a photodiode and an oscilloscope. The stimulus was a black line measuring $0.3^{\circ}$ in length at the viewing distance of $59 \mathrm{~cm}$. For 4 subjects the size of the line was increased up to $0.5^{\circ}$ to compensate for more peripheral presentation. The line was tilted $30^{\circ}$ to the left or right from vertical. 
The exact position of stimulus for occipital and parietal stimulation sites was determined for each individual during an initial localization phase. Participants were instructed to move the line stimulus into the area of the phosphene and position it as closely to the fixation as possible while maintaining full coverage of the line by the phosphene. Across subjects, stimulus locations ranged from $0.7^{\circ}$ to $4.6^{\circ}$ (with mean $1.7^{\circ}$ ) eccentricity for occipital and from $0.4^{\circ}$ to $6.2^{\circ}$ (with mean $2.3^{\circ}$ ) eccentricity for parietal conditions; overall stimulus locations did not differ significantly for occipital and parietal conditions (two-tailed $\mathrm{p}<0.11$ ), consistent with Mazzi et al. (under review). A fixation dot helped participants maintain fixation throughout the experiment.

We refer to the visual field in which the phosphene was perceived (right for 12 participants) as the experimental visual field and to the opposite visual field as the control visual field. In rare instances, and only during the orientation discrimination and visibility rating phase, a phosphene was reported in the control visual field; this occurred for only 4 out of the 18 subjects and even then on only a handful of trials (less than 20 from 1120 total trials). This most likely reflects false alarms rather than genuine phosphene sensations because ipsilateral phosphenes were never reported during the initial screening and positioning procedure when participants' main task was to report the presence and position of the phosphenes. For this reason, and because phosphenes in the control visual field were reported on very few trials, we classify the experimental and control visual fields according to the vast majority of trials. Stimulus location in the control visual field was mirrored from the experimental visual field location.

After stimulus locations were determined, participants performed a practice task of 60 trials without TMS. The practice task was identical to the experimental trials except that on a third of trials a dot instead of a line was presented to simulate partial TMS suppression of visual stimulus, on another third of trials no stimulus was presented. On each trial participants had to judge the tilt of the stimulus in a two-alternative forced-choice task and rate its visibility. If accuracy during practice on trials with line stimulus fell below 85-90\%, the size of the stimulus was increased. This ensured that the stimulus was clearly visible without TMS and that participants had practice with the task. In the TMS phase of the experiment, the line stimulus was presented on every trial. As in the practice session, participants had to first indicate the tilt of the line, left or right, or guess if they didn't see it, and then rate how visible the stimulus was. They were instructed to use a scale from 1 to 4 where $1=$ "clearly visible", 2 = "pretty visible", 3 = "I saw something, but I don't know which way the line was tilted", and 4 = "I didn't see anything."

\section{Design and TMS parameters}

The TMS phase of the experiment was separated into four 1-1.5 hr sessions, run on separate days, with two consecutive sessions devoted to either occipital or parietal stimulation sites. The order of stimulation sites was counterbalanced across participants. At the beginning of each session phosphene threshold (i.e. TMS stimulus intensity) was determined using a staircase method (Abrahamyan et al., 2011). TMS intensity was then increased to $140 \%$ of phosphene threshold for the remainder of that session. Phosphene threshold for occipital sites ranged from $49 \%$ to $71 \%$ of machine output, with a mean of $57 \%$, which meant that

Exp Brain Res. Author manuscript; available in PMC 2015 June 01. 
stimulation intensity ranged from $69 \%$ to $99 \%$ (mean of $80 \%$ ) of machine output during the visibility phase of the experiment. Phosphene threshold for parietal sites ranged from $50 \%$ to $78 \%$ of machine output, with mean of $61 \%$, resulting in stimulation outputs during the visibility phase of the study that ranged from $70 \%$ to $100 \%$, with mean of $86 \%$. Stimulation intensity required to elicit parietal phosphenes was on average significantly higher than intensity required to elicit occipital phosphenes (one-tailed $\mathrm{p}<0.003$, consistent with other studies (Fried et al., 2011; Mazzi et al, under review).

During each session four blocks of 140 trials were administered. Line tilt (left or right) and line location (experimental or control visual field) was randomized, but equally likely across each block of trials. TMS was applied on half of the trials in $10 \mathrm{~ms}$ steps from onset of the stimulus covering the range of stimulus onset asynchronies (SOAs) from 0 to $130 \mathrm{~ms}$. The stimulus-TMS SOAs and no-TMS trials were randomized within each block of trials. There were a total of 448 TMS ( 32 per SOA) and 112 no-TMS trials when the stimulus appeared in the same visual field as a phosphene (experimental visual field); there were a total of 112 TMS ( 8 per SOA) and 448 no-TMS trials when stimulus appeared in the control, nophosphene visual field. This design encouraged participants to maintain fixation and prevented differential response biases for TMS and no-TMS trials or for stimulus location. The control visual field presentations also helped to rule out any nonspecific TMS effects (see Koivisto, Railo \& Salimen-Vaparanta, 2011).

At the beginning of each block of 140 trials we verified that the stimulus appeared in the location of the phosphene. The stimulation site was recorded and coil placement was monitored on-line using Brainsight neuronavigation system (Rogue Research, Montreal, Canada). A chin rest stabilized the head. Biphasic single TMS pulses were administered using a Magstim 220 Rapid Stimulator with a $70 \mathrm{~mm}$ figure-of-eight coil, handle pointing up.

\section{RESULTS}

Proportion of correct responses from line discrimination trials were square root transformed, and average stimulus visibility rating at each SOA was computed for every participant. These data were submitted to a 2 (visual field: control or experimental) $\times 15$ (SOA: 0-130 ms and no-TMS) repeated measures ANOVA separately for each task and for each occipital and parietal stimulation sites. When assumptions of sphericity were violated, we used Greenhouse-Geisser corrections. Further, for post-hoc t-tests we compared accuracy or visibility ratings across the range of SOAs against the no-TMS condition and applied the Holm-Bonferroni correction for multiple comparisons.

Figure 1 shows results obtained for the occipital stimulation sites. The accuracy data revealed a significant main effect of visual field $(F(1,17)=8.775$, $p<0.009)$, reflecting overall higher accuracy for stimuli appearing in the control as compared to the experimental visual field, consistent with the retinotopic effect of TMS over the occipital cortex. The significant main effect of SOA $(F(4.737,80.532)=2.940, \mathrm{p}<0.019)$ indicates that overall stimulus visibility varied across the range of stimulus-TMS SOAs. The significant interaction between visual field and SOA $(\mathrm{F}(6.358,108.078)=4.056, \mathrm{p}<0.001)$ reflects greater and more 
consistent changes in stimulus visibility as a function of SOA in the experimental visual field than in the control visual field and is consistent with the retinotopic nature of TMS over the occipital cortex. In the experimental (i.e. phosphene) visual field line accuracy decreased starting at SOA $60 \mathrm{~ms}$, reaching a minimum at $80 \mathrm{~ms}$, comparable to previous reports of suppression from occipital TMS (e.g. Amassian et al., 1989; Corthout et al., 1999). The outcome of post-hoc t-tests is presented in Table 1 . The t-tests reveal significant reduction of stimulus visibility at SOAs $6070,80,90$ and $100 \mathrm{~ms}$.

Subjective line visibility ratings produced a similar pattern of results. The main effects of visual field $(\mathrm{F}(1,17)=5.042, \mathrm{p}<0.038)$, $\operatorname{SOA}(\mathrm{F}(3.552,60.377)=3.323, \mathrm{p}<0.001)$, as well as the interaction between these factors $(F(4.601,78.223)=4.448$, $p<0.002)$ were significant. This reflects overall higher visibility ratings for stimuli appearing in the control than in the experimental visual field, with most pronounced decrease in perceived visibility at SOAs 60-100 ms for stimuli in the experimental visual field only, consistent with previous findings (e.g. de Graaf, Goebel, \& Sack, 2011; Koivisto, Mäntylä, \& Silvanto, 2010, 2012; Koivisto et al., 2011; Railo \& Koivisto, 2012). T-tests of ratings against the no-TMS condition reveal significant decreases in subjective stimulus visibility at SOAs 80, 90, 100, $110 \mathrm{~ms}$ (see Table 1).

Figure 2 shows the results obtained for the parietal stimulation sites. We first report the results of the 2-way ANOVA on accuracy data. The main effect of visual field was not significant $(\mathrm{p}=0.421)$. More importantly, there was no significant interaction between the factors of visual field and SOA ( $\mathrm{p}=0.193)$ indicating that stimulus visibility did not vary reliably across the stimulus-TMS SOAs across the two visual fields. Furthermore, post-hoc $\mathrm{t}$-tests for stimulus accuracy in the experimental visual field against no-TMS trials were not significant either (see Table 1). Thus, in contrast to the occipital data we see no reliable suppression windows in the parietal data.

The main effect of SOA also did not reach significance $(F(5.376,91.394)=1.995, p=0.082)$, but it might be considered marginally significant by some. Given the lack of effect of visual field and an effect of SOA that is approaching significance, one might question whether the ipsilateral visual field is a valid control for parietal stimulation sites. Abundant interhemispheric connections between the parietal cortices (Ffytche, Howseman, Edwards, Sandeman, \& Zeki, 2000; Gross, Bender, \& Mishkin, 1997; Marzi, Antonini, Di Stefano, \& Legg, 1982) contribute to a less spatially precise topography in visual parietal areas as compared to that of the occipital cortex. Consistent with this neuroanatomy, parietal phosphenes are less precisely organized in retinotopic space than occipital phosphenes (Fried et al., 2011; Mazzi et al., under review). Indeed, interhemispheric connections between the parietal cortices might allow for spread of TMS induced neural activity from the contralateral (i.e. experimental) to the ipsilateral (i.e. control) hemifield (Marzi et al., 2009), resulting in changes in visibility for stimuli presented in either visual field. However, even when data are collapsed across the experimental and control visual fields, stimulus accuracy at any SOA does not differ significantly from accuracy in no-TMS trials after a Holm-Bonferroni correction for multiple comparisons, nor does the grand average accuracy across all SOA conditions differs significantly from no-TMS performance $(\mathrm{p}=0.085)$. The lack of consistent SOA effects when visual fields were combined should be expected when 
one considers that even if both visual fields were suppressed the timing of the suppression should differ given that it takes time for the induced signal to cross hemispheres. Thus, in a final attempt to reveal significant suppression from parietal TMS, we computed separate one-way ANOVAs for each visual field comparing accuracy across the range of SOAs. Neither the control $(\mathrm{F}(4.334,73.671)=1.668, \mathrm{p}=0.162)$ nor experimental visual fields $(\mathrm{F}(4.008,68.131)=2.083, \mathrm{p}=0.092)$ revealed significant effects of SOA.

Analyses of the subjective stimulus ratings revealed no significant main effects nor interactions (all ps>0.121), which further suggest that stimulus suppression did not vary reliably across SOA for parietal TMS (also see Table 1). In short, unlike with occipital TMS, we were unable to reliably interfere with stimulus visibility in either objective or subjective tasks using parietal stimulation.

Although there were no consistent suppression intervals at the group level during parietal stimulation, for some individual subjects visibility appeared to drop below baseline at some SOAs (see Figure 3A). However, even among these subjects there was considerable variability in terms of the SOAs that exhibited reduced visibility, raising two possibilities: either the suppression intervals are idiosyncratic across subjects or even these data simply reflect noise in the visibility curves. To distinguish between these alternatives, we reran four of the participants who showed some indication of TMS suppression with parietal stimulation to see if we could replicate the same visibility effects within subject. The visibility patterns for each subject were again variable across SOAs, but unfortunately they bore no relation to the patterns obtained in Experiment 1 (see Figure 3B). Even when data of these subjects were collapsed across the two runs, neither the main effect of SOA nor the interaction between SOA and visual field were significant (both ps>0.17). Hence, we conclude that patterns we observed in parietal stimulation data simply reflect noise. Thus, for the same stimulation parameters as occipital TMS, we were unable to observe comparable or even shifted stimulus suppression intervals for parietal TMS.

\section{DISCUSSION}

TMS to the occipital cortex regions that generate phosphene or scotoma sensations reduces visibility of stimuli. Given that TMS to parietal cortex also elicits sensations of phosphenes (Fried et al., 2011; Marzi et al., 2009) we tested whether parietal TMS might also reduce visibility of stimuli. Using TMS-generated phosphenes to guide both coil and stimulus placement, in a within-subject experiment we compared stimulus visibility across a range of stimulus-TMS SOAs during occipital and parietal stimulation conditions. We replicate the previously reported suppression of visual stimuli approximately $80-100 \mathrm{~ms}$ after TMS is applied to the occipital cortex (e.g. Amassian et al., 1989; Corthout et al., 1999). However, using the exact same procedure as used for occipital TMS, i.e. by positioning stimulus in the region of a phosphene and adjusting stimulation intensity by a set factor above the phosphene threshold, we were unable to elicit consistent suppression patterns with parietal TMS.

Several possibilities might explain our inability to suppress stimulus visibility with parietal TMS. First, although we followed the exact same procedure to elicit occipital and parietal 
phosphenes and subsequently reduce stimulus visibility, there were still some qualitative and quantitative differences between the two conditions. For example, on average, parietal phosphene thresholds required higher TMS stimulation than occipital phosphenes (Fried et al., 2011; Mazzi et al., under review). Because cortical stimulation decreases with coil to cortex distance (Stokes et al., 2007), it is possible that the greater parietal stimulation intensity reflects larger distances between the skull and the parietal locus of phosphene stimulation than the occipital locus. Alternatively, the stimulation differences also might reflect the need for greater cortical stimulation in the parietal site itself to produce comparable experience of phosphenes. Despite these higher TMS intensities, some participants still indicated that parietal phosphenes were less vivid, less pronounced, had less clearly defined borders, were smaller in size, and occurred less frequently than occipital phosphenes (Mazzi et al., under review).

Weaker parietal phosphene sensations raise the possibility that even stronger TMS intensities might have led to visual suppression comparable to that produced by occipital TMS. However, we note that it is not fully clear how phosphene and TMS masking intensities map onto each other; occipital scotomas have been show to require lower (Hallett, 2000), similar (Kammer et al., 2005a) or higher (Kastner et al., 1998) TMS intensity than phosphenes. Kammer et al. (2005a) specifically indicate that phosphene thresholds were a factor of 0.59 below thresholds required to elicit visual masking with TMS applied to the occipital cortex. In our procedure TMS intensity for line orientation and visibility rating task was set at a factor of 0.7 above phosphene threshold. Nonetheless, the lack of consensus regarding the required TMS intensity means that an even higher (or perhaps lower) ratio between phosphene threshold and masking intensity might be more effective for parietal stimulation.

Stronger TMS intensity for parietal phosphenes and, possibly, parietal scotomas might be required if parietal phosphenes arise from an occipitotemporal mechanism (Fried et al., 2011). In this framework, brain activation in occipital cortex 20-40 ms after TMS to parietal cortex areas that are known to elicit phosphenes (Parks et al., 2013) would be the neural signature of parietal phosphenes. Thus, if parietal phosphenes are a consequence of the TMS stimulation feeding back on occipitotemporal cortex it may be that the signal weakens during transmission to the occipital cortex (Parks et al., 2013). A weaker signal may still be sufficient to induce a sensation of a phosphene, but it may not be strong enough to reduce visibility of a physical stimulus. Indeed, it is plausible that a feedback signal, regardless of how it is generated, is intrinsically weaker than the feedforward signal initiated by a physical stimulus. Even among theories that specify a role for feedback in vision, the feedback is weaker than the feedforward signal. Indeed, backward masking is thought to occur because the feedforward signal of the second, mask stimulus overrides the weaker feedback signal of the first, target stimulus (Di Lollo, Enns \& Rensink, 2000; Fahrenfort, Scholte, \& Lamme, 2007; Lamme \& Roelfsema, 2000). Whether feedback is required for awareness (Lamme \& Roelfsema, 2000), primarily for attentional modulation (Macknik \& Martinez-Conde, 2007), for filling-in of details after a general gist of a scene is established (Ahissar, Nahum, Nelken, \& Hochstein, 2009; Bullier, 2001; Hochstein \& Ahissar, 2002), or for modulating activity in lower level sensory regions based on expectation (Panichello, Cheung, \& Bar, 2012), it is 
typically described as playing an augmenting role. On top of this, in our study the feedback was generated without its accompanying and initial feedforward activity, potentially making it an even less robust signal. Taking these considerations together, one might predict that TMS-induced feedback would not be sufficient to interfere with the feedforward signal.

Of course, it is also possible that the phosphene experience induced by parietal stimulation does not depend on activity in occipitotemporal cortex, but instead is due to the parietal stimulation itself. Parietal regions near the P3/P4 electrode sites (Herwig et al., 2003) that we stimulated have been shown to be visually responsive (Konen \& Kastner, 2008; Swisher et al., 2007), raising the possibility that the experience of phosphenes does not depend on the indirect occipitotemporal stimulation. Additionally, hemianopic patients with completely damaged primary visual cortices consistently report sensations of phosphenes after parietal TMS (Mazzi et al., under review), which suggests that primary visual cortex may not be necessary for perception of parietal phosphenes. Thus, it is feasible that parietal and occipital phosphenes arise from distinct mechanisms, and therefore may not be expected to lead to all the same perceptual effects (e.g. scotomas and suppression).

Finally, regardless of whether the TMS-induced phosphene experience resulted from indirect occipitotemporal activity or separate parietal mechanisms, it is possible that the same stimuli used to assess occipital TMS suppression are not optimal for suppression by parietal stimulation. For example, near-threshold stimuli or gabors that more closely resemble phosphenes or scotomas might be easier to suppress with parietal stimulation than tilted lines used in the present study.

Taking all these factors into account, we cannot conclude that parietal stimulation cannot suppress vision. However, the experiments described represent a good first attempt. Very similar stimulation parameters administered under identical protocols to elicit experiences of phosphenes produced clear suppression of visibility with TMS to occipital cortex, but no such suppression with TMS to parietal cortex. Further research is thus necessary to determine whether phosphene-guided parietal TMS can under some circumstances suppress vision and, if so, how it differs from occipital stimulation and suppression.

\section{Acknowledgments}

We thank Dustin Martin, Martin Prete and Lu Echo Ye for assistance with data collection. This research was conducted while Evelina Tapia was a postdoctoral trainee in the Cognitive Psychophysiology Training Program at the Department of Psychology, University of Illinois at Urbana-Champaign (National Institute of Mental Health National Research Service Award MH19554 to the University of Illinois).

\section{References}

Abrahamayan A, Clifford CWG, Ruzzoli M, Phillips D, Arabzadeh E, et al. Accurate and rapid estimation of phosphene thresholds (REPT). PLoS ONE. 2011; 6:e22342. [PubMed: 21799833]

Ahissar M, Nahum M, Nelken I, Hochstein S. Reverse hierarchies and sensory learning. Philos Trans R Soc Lond B Biol Sci. 2009; 364:285-299. [PubMed: 18986968]

Amassian VE, Cracco RQ, Maccabee PJ, Cracco JB, Rudell A, Eberle L. Suppression of visual perception by magnetic coil stimulation of human occipital cortex. Electroencephalogr Clin Neurophysiol. 1989; 74:458-462. [PubMed: 2480226]

Exp Brain Res. Author manuscript; available in PMC 2015 June 01. 
Barker AT, Freeston IL, Jalinous R, Merton PA, Morton HB. Magnetic stimulation of the human brain. J Physiol (Lond). 1985; 369:3P.

Bullier J. Integrated model of visual processing. Brain Res Brain Res Rev. 2001; 36:96-107. [PubMed: 11690606]

Corthout E, Uttl B, Walsh V, Hallett M, Cowey A. Timing of activity in early visual cortex as revealed by transcranial magnetic stimulation. Neuroreport. 1999; 10:2631-2634. [PubMed: 10574382]

Corthout E, Uttl B, Ziemann U, Cowey A, Hallett M. Two periods of processing in the (circum)striate visual cortex as revealed by transcranial magnetic stimulation. Neuropsychologia. 1999; 37:137145. [PubMed: 10080371]

de Graaf TA, Goebel R, Sack AT. Feedforward and quick recurrent processes in early visual cortex revealed by TMS? Neuroimage. 2011; 61:651-659. [PubMed: 22032946]

de Graaf TA, Herring J, Sack AT. A chronometric exploration of high-resolution 'sensitive TMS masking' effects on subjective and objective measures of vision. Exp Brain Res. 2011; 209:19-27. [PubMed: 21161191]

Di Lollo V, Enns JT, Rensink RA. Competition for consciousness among visual events: the psychophysics of reentrant processes. J Exp Psychol Hum Percept Psychol. 2000; 129:481-507.

Fahrenfort JJ, Scholte HS, Lamme VAF. Masking disrupts reentrant processing in human visual cortex. J Cog Neurosci. 2007; 9:1488-97.

Felleman D, Van Essen D. Distributed hierarchical processing in the primate cerebral cortex. Cereb Cortex. 1991; 1:1-47. [PubMed: 1822724]

Fernandez E, Alfaro A, Tormos JM, Climent R, Martinez M, Vilanova H, Walsh V, Pascual-Leone A. Mapping of the human visual cortex using image-guided transcranial magnetic stimulation. Brain Res Brain Res Protoc. 2002; 10:115-124. [PubMed: 12431711]

ffytche DH, Howseman A, Edwards R, Sandeman DR, Zeki S. Human area V5 and motion in the ipsilateral visual Weld. Eur J Neurosci. 2000; 12:3015-3025. [PubMed: 10971642]

Fried PJ, Elkin-Frankston S, Rushmore RJ, Hilgetag CC, Valero-Cabre A. Characterization of visual percepts evoked by noninvasive stimulation of the human posterior parietal cortex. PLoS ONE. 2011; 6(11):e27204. [PubMed: 22087266]

Gross CG, Bender DB, Mishkin M. Contributions of the corpus callosum and the anterior commissure to visual activation of inferior temporal neurons. Brain Res. 1977; 131:227-239. [PubMed: 407973]

Hallett M. Transcranial magnetic stimulation and the human brain. Nature. 2000; 406:147-150. [PubMed: 10910346]

Herwig U, Satrapi P, Schonfeldt-Lecuona C. Using the international 10-20 EEG system for positioning of transcranial magnetic stimulation. Brain Topogr. 2003; 16:95-99. [PubMed: 14977202]

Hochstein S, Ahissar M. View from the top: Hierarchies and reverse hierarchies in the visual system. Neuron. 2002; 36:791-804. [PubMed: 12467584]

Jacobs C, Goebel R, Sack AT. Visual awareness suppression by pre-stimulus brain stimulation: a neural effect. Neuroimage. 2012; 59:616-624. [PubMed: 21840406]

Kamitani Y, Shimojo S. Manifestation of scotomas created by transcranial magnetic stimulation of human visual cortex. Nat Neurosci. 1999; 2:767-771. [PubMed: 10412068]

Kammer T. Phosphenes and transient scotomas induced by magnetic stimulation of the occipital lobe: Their topographic relationship. Neuropsychologia. 1999; 37:191-198. [PubMed: 10080376]

Kammer T. Visual masking by transcranial magnetic stimulation in the first 80 milliseconds. Adv Cogn Psychol. 2007; 3:177-179. [PubMed: 20517507]

Kammer T, Puls K, Erb M, Grodd W. Transcranial magnetic stimulation in the visual system. II. Characterization of induced phosphenes and scotomas. Exp Brain Res. 2005a; 160:129-140. [PubMed: 15368087]

Kammer T, Puls K, Strasburger H, Hill NJ, Wichmann FA. Transcranial magnetic stimulation in the visual system. I. The psychophysics of visual suppression. Exp Brain Res. 2005b; 160:118-128. [PubMed: 15368086]

Exp Brain Res. Author manuscript; available in PMC 2015 June 01. 
Kastner S, Demmer I, Ziemann U. Transient visual field defects induced by transcranial magnetic stimulation over human occipital pole. Exp Brain Res. 1998; 118:19-26. [PubMed: 9547074]

Koivisto M, Mäntylä T, Silvanto J. The role of early visual cortex (V1/V2) in conscious and unconscious visual perception. Neuroimage. 2010; 51:828-834. [PubMed: 20188199]

Koivisto M, Mäntylä T, Silvanto J. Unconscious response priming by shape depends on geniculostriate visual projection. Eur J Neurosci. 2012; 35:623-633. [PubMed: 22304409]

Koivisto M, Railo H, Salminen-Vaparanta N. Transcranial magnetic stimulation of early visual cortex interferes with subjective visual awareness and objective forced-choice performance. Conscious Cogn. 2011; 20:288-298. [PubMed: 20863717]

Konen CS, Kastner S. Two hierarchically organized neural systems for object information in human visual cortex. Nature Neurosci. 2008; 11:224-231. [PubMed: 18193041]

Knight, R.; Mazzi, C.; Savazzi, S. Shining new light on dark perceptions: Visual percepts induced by TMS of the occipital cortex. Poster presented at the annual Cognitive Neuroscience Society (CNS) meeting; San Francisco, CA. April 13-16; 2013.

Lamme VAF, Roelfsema PR. The distinct modes of vision offered by feedforward and recurrent processing. Trends Neurosci. 2000; 23:571-579. [PubMed: 11074267]

Lewis JW, Van Essen DC. Mapping of architectonic subdivisions in the macaque monkey, with emphasis on parieto-occipital cortex. J Comp Neurol. 2000; 428:79-111. [PubMed: 11058226]

Macknik S, Martinez-Conde S. The role of feedback in visual masking and visual processing. Adv Cogn Psychol. 2007; 3:125-152. [PubMed: 20517504]

Marg E, Rudiak D. Phosphenes induced by magnetic stimulation over the occipital brain: Description and probable site of stimulation. Optom Vis Sci. 1994; 71:301-311. [PubMed: 8065706]

Marzi CA, Antonini A, Di Stefano M, Legg CR. The contribution of the corpus callosum to receptive Welds in the lateral suprasylvian visual areas of the cat. Behav Brain Res. 1982; 4:155-176. [PubMed: 7059374]

Marzi C, Mancini F, Savazzi S. Interhemispheric transfer of phosphenes generated by occipital versus parietal transcranial magnetic stimulation. Exp Brain Res. 2009; 192:431-441. [PubMed: 18663438]

Morgan M. Making holes in the visual world. Nat Neurosci. 1999; 2:685-686. [PubMed: 10412051]

Orban GA, Claeys K, Nelissen K, Smans R, Sunaert S, Todd JT, Wardak C, Durand JB, Vanduffel W. Mapping the parietal cortex of human and non-human primates. Neuropsychologia. 2006; 44:2647-2667. [PubMed: 16343560]

Panichello M, Cheung O, Bar M. Predictive feedback and conscious visual experience. Front Psychol. 2012; 3:620. [PubMed: 23346068]

Parks, NA.; Beck, D.; Low, KA.; Maclin, EL.; Tapia, E.; Savazzi, S.; Mazzi, C.; Fabiani, M.; Gratton, G. Dynamic measurement of functional connectivity using simultaneous fast optical imaging and magnetic stimulation. Talk presented at the annual Society for Psychophysiological Research (SPR) meeting; Florence, Italy. October 2-6; 2013.

Railo H, Koivisto M. Two means of suppressing visual awareness: a direct comparison of visual masking and transcranial magnetic stimulation. Cortex. 2012; 48:333-343. [PubMed: 21232737]

Sack AT, van der Mark T, Schuhmann T, Schwarzbach J, Goebel R. Symbolic action priming relies on intact neural transmission along the retino-geniculo-striate pathway. Neuroimage. 2009; 44:284293. [PubMed: 18721890]

Silver MA, Kastner S. Topographic maps in human frontal and parietal cortex. Trends Cogn Sci. 2009; 13:488-495. [PubMed: 19758835]

Silver MA, Ress D, Heeger DJ. Topographic maps of visual spatial attention in human parietal cortex. J Neurophysiol. 2005; 94:1358-1371. [PubMed: 15817643]

Stokes MG, Chambers CD, Gould IC, English T, McNaught E, McDonald O, Mattingley JB. Distanceadjusted motor threshold for transcranial magnetic stimulation. Clin Neurophysiol. 2007; 118:1617-1625. [PubMed: 17524764]

Swisher JD, Halko MA, Merabet LB, McMains SA, Somers DC. Visual topography of human intraparietal sulcus. J Neurosci. 2007; 27:5326-5337. [PubMed: 17507555]

Exp Brain Res. Author manuscript; available in PMC 2015 June 01. 
Thielscher A, Reichenbach A, Uğurbil K, Uludağ K. The cortical site of visual suppression by transcranial magnetic stimulation. Cereb Cortex. 2010; 20:328-338. [PubMed: 19465739]

Webster MJ, Bachevalier J, Ungerleider LG. Connections of inferior temporal areas TEO and TE with parietal and frontal cortex in macaque monkeys. Cereb Cortex. 1994; 4:470-483. [PubMed: 7530521] 

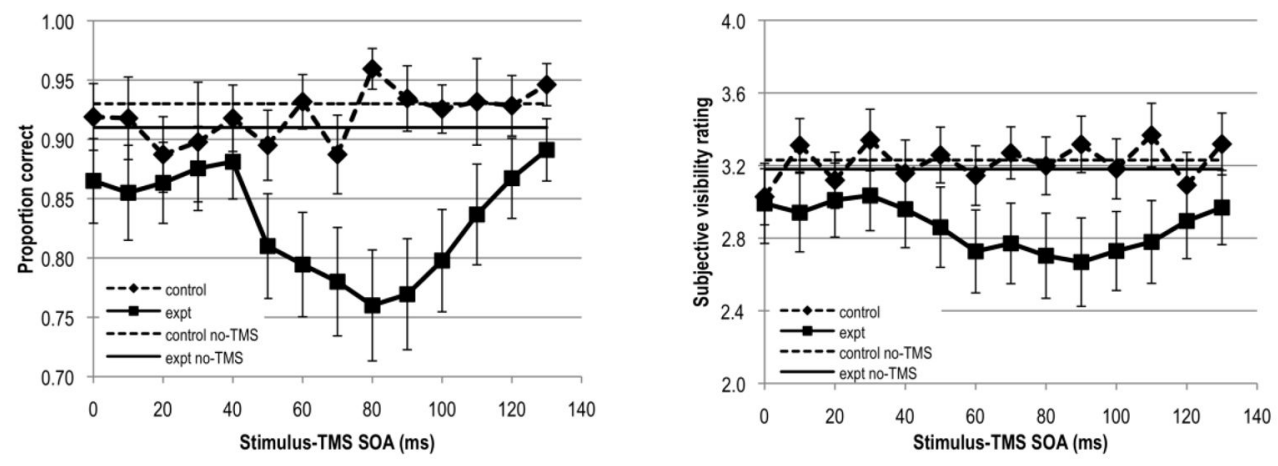

Figure 1.

Results obtained for occipital stimulation sites. Left panel shows line accuracy and right panel shows subjective line visibility rating data. Error bars denote \pm 1 standard error of the mean computed for the sample. 

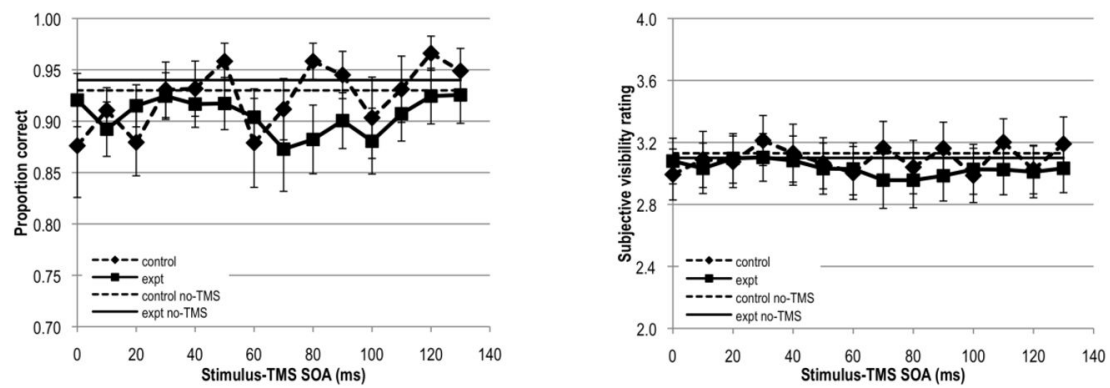

Figure 2.

Results obtained for parietal stimulation sites. Left panel shows line accuracy and right panel shows subjective line visibility rating data. Error bars denote \pm 1 standard error of the mean computed for the sample. 

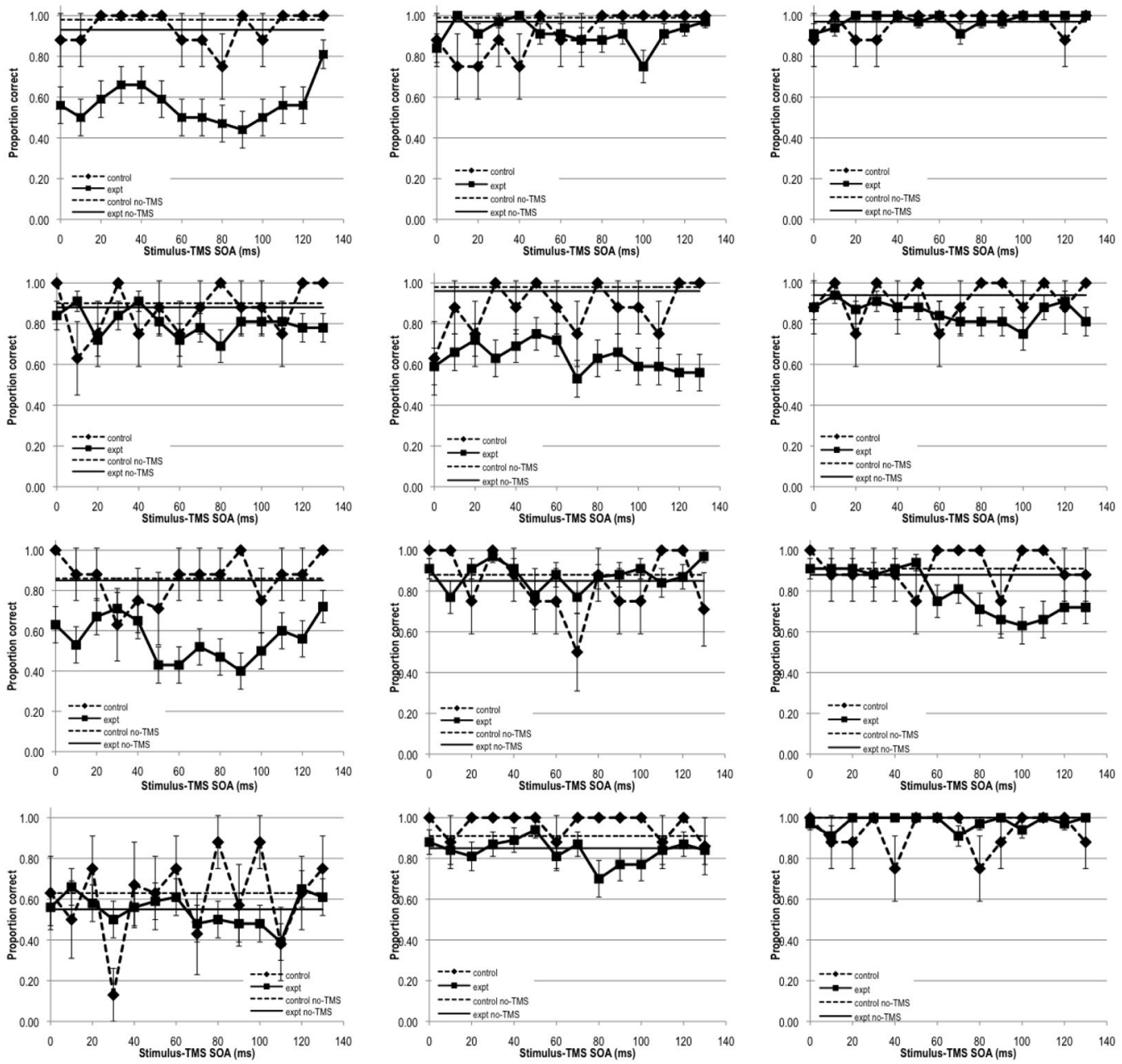

Figure 3.

Results obtained for parietal stimulation sites for four subjects. Left panels show data from the initial experiment, while right panels show data for the same four subjects from the repeated parietal stimulation sessions. Error bars denote \pm 1 standard error of the mean computed separately for each subject. 


\section{Table 1}

Statistical values from comparison to no-TMS trials

Occipital cortex

\begin{tabular}{|c|c|c|c|c|}
\hline & \multicolumn{2}{|c|}{ Line tilt accuracy } & \multicolumn{2}{|c|}{ Visibility rating } \\
\hline & t-value & $p$ & t-value & $p$ \\
\hline $0 \mathrm{~ms}$ & -1.82 & 0.043 & -0.99 & 0.169 \\
\hline $10 \mathrm{~ms}$ & -1.63 & 0.061 & -1.28 & 0.110 \\
\hline $20 \mathrm{~ms}$ & -1.92 & 0.036 & -0.92 & 0.187 \\
\hline $30 \mathrm{~ms}$ & -1.55 & 0.070 & -0.89 & 0.194 \\
\hline $40 \mathrm{~ms}$ & -1.57 & 0.068 & -1.27 & 0.111 \\
\hline $50 \mathrm{~ms}$ & -2.57 & 0.010 & -1.71 & 0.053 \\
\hline $60 \mathrm{~ms}$ & -2.91 & $0.005^{*}$ & -2.22 & 0.021 \\
\hline $70 \mathrm{~ms}$ & -3.34 & $0.002^{*}$ & -2.14 & 0.024 \\
\hline $80 \mathrm{~ms}$ & -3.71 & $0.001^{*}$ & -2.39 & $0.015^{*}$ \\
\hline $90 \mathrm{~ms}$ & -3.51 & $0.002^{*}$ & -2.46 & $0.013^{*}$ \\
\hline $100 \mathrm{~ms}$ & -3.34 & $0.002^{*}$ & -2.64 & $0.009^{*}$ \\
\hline $110 \mathrm{~ms}$ & -2.67 & 0.008 & -2.25 & $0.019^{*}$ \\
\hline $120 \mathrm{~ms}$ & -1.61 & 0.063 & -1.92 & 0.036 \\
\hline $130 \mathrm{~ms}$ & -1.60 & 0.065 & -1.49 & 0.078 \\
\hline
\end{tabular}

$\underline{\text { Parietal cortex }}$

\begin{tabular}{lrlrl} 
& \multicolumn{2}{c}{ Line tilt accuracy } & \multicolumn{2}{c}{ Visibility rating } \\
\cline { 2 - 5 } & t-value & $\boldsymbol{p}$ & t-value & $\boldsymbol{p}$ \\
\hline $0 \mathrm{~ms}$ & -0.67 & 0.256 & -0.20 & 0.422 \\
$10 \mathrm{~ms}$ & -1.90 & 0.038 & -0.61 & 0.276 \\
$20 \mathrm{~ms}$ & -1.01 & 0.163 & -0.05 & 0.482 \\
$30 \mathrm{~ms}$ & -0.57 & 0.287 & 0.00 & 0.499 \\
$40 \mathrm{~ms}$ & -1.04 & 0.156 & -0.17 & 0.436 \\
$50 \mathrm{~ms}$ & -1.27 & 0.111 & -0.68 & 0.253 \\
$60 \mathrm{~ms}$ & -1.62 & 0.062 & -0.67 & 0.256 \\
$70 \mathrm{~ms}$ & -1.76 & 0.049 & -1.26 & 0.113 \\
$80 \mathrm{~ms}$ & -1.96 & 0.034 & -1.19 & 0.125 \\
$90 \mathrm{~ms}$ & -1.87 & 0.039 & -1.07 & 0.149 \\
$100 \mathrm{~ms}$ & -2.05 & 0.028 & -0.73 & 0.239 \\
$110 \mathrm{~ms}$ & -1.32 & 0.103 & -0.84 & 0.207 \\
$120 \mathrm{~ms}$ & -0.50 & 0.313 & -1.00 & 0.165 \\
$130 \mathrm{~ms}$ & -0.48 & 0.319 & -0.78 & 0.223 \\
\hline
\end{tabular}

* Statistically significant after Holm-Bonferroni correction 